\title{
Psychometric Properties of the Brazilian Version of the Friendship Quality Questionnaire in a Community Sample of Children and Early Adolescents*
}

\section{Propiedades psicométricas de la versión brasileña del Cuestionario sobre Calidad de la Amistad en una muestra de niños y preadolescentes}

doi:10.11144/Javeriana.UPSY13-2.ppbv

Para citar este artículo: DeSousa, D. A., Koller, S. H., Wendt, G. W., \& Lisboa, C. (2014). Psychometric properties of the Brazilian version of the Friendship Quality Questionnaire in a community sample of children and early adolescents. Universitas Psychologica, 13(2), 423-431. doi:10.11144/ Javeriana.UPSY13-2.ppbv

Empirical research. This project was funded by the Brazilian National Council for Scientific and Technological Development (Conselho Nacional de Desenvolvimento Científico e Tecnológico [CNPq]). We thank Ana Maria Faraco de Oliveira, Ph.D., Mauro Luis Vieira, Ph.D., and their research teams for the collaborative work in this research project. We also thank Bruno Figueiredo Damásio, M.Sc., for his important contributions revising the statistical analysis. Guilherme W. Wendt thanks CAPES for the Doctorate Scolarship Grant - Goldsmiths, University of London (Process BEX 893813-3). Finally, we thank all children and families involved in this study.

** Center for Psychological Studies on At Risk Populations (CEP-Rua) and Anxiety Disorders Outpatient Program for Child and Adolescent Psychiatry (PROTAIA). Graduate Program in Psychology, Institute of Psychology, Universidade Federal do Rio Grande do Sul (UFRGS) 2600 Ramiro Barcelos, Room 104. 90035-003, Porto Alegre, RS, Brazil. Telephone: + 55 513308 5150.E-mail: diogo.a.sousa@gmail.com

**** Center for Psychological Studies on At Risk Populations (CEP-Rua), Graduate Program in Psychology, Institute of Psychology, Universidade Federal do Rio Grande do Sul (UFRGS), Porto Alegre, RS, Brazil. E-mail: silvia.koller@gmail.com

***** Graduate Program in Clinical Psychology, Universidade do Vale do Rio dos Sinos (UNISINOS), São Leopoldo, RS, Brazil. E-mail: guilhermewwendt@ gmail.com

**wask Graduate Program in Clinical Psychology, Universidade do Vale do Rio dos Sinos (UNISINOS), São Leopoldo, RS, Brazil.E-mail: lisboacaro@gmail.com
Recibido: octubre 9 de 2012 | Revisado: enero 21 de 2013 |Aceptado: mayo 26 de 2013

$$
\begin{aligned}
& \text { Diogo Araújo DeSousa ** } \\
& \text { Silvia Helena Koller *** }
\end{aligned}
$$

Universidade Federal do Rio Grande do Sul, Porto Alegre, Brazil

$$
\text { GUILHERME WELTER WENDT **** }
$$

CAROLINA LisBOA ******

Universidade do Vale do Rio dos Sinos, São Leopoldo, Brazil

\section{A B S T R A C T}

The Friendship Quality Questionnaire (FQQ) is an instrument designed to assess children's perceptions of qualities of their friendship. The aim of this study was to investigate psychometric properties of the FQQ in a Brazilian community sample of children and early adolescents. Participants were 274 students aged $9-13$ years $(M=10.46 ; S D=0.81), 52.2 \%$ boys, who completed the Brazilian version of the FQQ. Confirmatory factor analysis demonstrated the six-factor original structure of the FQQ fit this sample well after the exclusion of one item related to betrayal. Except for the "Conflict" subscale, all factors presented high positive intercorrelations. The total and subscale scores showed good internal consistency. Girls scored higher on the total score and the "Validation and Caring" and "Intimate Exchange" subscale scores as compared to boys. Our findings suggest the FQQ presented good evidences of validity and reliability to assess friendship quality in Brazilian children and adolescents.

Keywords

Friendship, Friendship Quality Questionnaire, psychometrics, validation.

\section{RESUMEN}

El Cuestionario sobre Calidad de la Amistad (Friendship Quality Questionnaire [FQQ]) es un instrumento desarrollado para medir las percepciones de los niños acerca de la cualidad de sus amistades. El objetivo de este estudio fue determinar las propiedades psicométricas del FQQ en una muestra de niños y adolescentes de una comunidad en Brasil. 274 estudiantes de 9-13 años de edad $(M=10.46 ; \mathrm{DE}=0.81), 52.2 \%$ chicos, respondieron a la versión brasileña del FQQ. El análisis factorial confirmatorio muestra la estructura original de seis factores del FQQ después de la exclusión de un ítem relacionado con traición. A excepción de la subescala "Conflicto", los demás factores presentaron altas intercorrelaciones positivas. La escala total y todas las subescalas mostraron adecuada consistencia interna. Las niñas tuvieron puntuaciones más elevadas en la escala total y en las subescalas "Validación y Cuidado" y "Cambios Íntimos" cuando se compararon con los chicos. Nuestros resultados sugieren que el FQQ presenta adecuadas evidencias de validación y confiabilidad para la medida de cualidad en la amistad de niños y adolescentes brasileños. 
Palabras clave

Amistad, Cuestionario de Cualidad en Amistad, psicometría, validación.

Friendship relationships are a ubiquitous experience for children of all ages, and multiple benefits are associated to good quality friendships in child development (Berndt, 2002; Bukowski, Motzoi, \& Meyer, 2009). A friendship can be defined as a mutual, strong, and positive affective relationship between two persons that are expected to be available for each other to offer companionship, support, and help when necessary. Among school-age children, friends tend to spend a lot of time together, sharing interests and activities, engaged in an intimate relationship characterized by crescent self-disclosure (Bukowski et al., 2009).

Friendship quality is a construct that refers to an individual's perception about a specific friendship (Kiesner, Nicotra, \& Notari, 2005). Relationships between friends that present good quality features have been associated to various positive direct and indirect effects on children (Berndt, 2002). For instance, they have been associated to higher levels of global self-worth (Fordham \& Stevenson-Hinde, 1999), protection from feelings of loneliness, social dissatisfaction and, by that, from depression symptoms (Nangle, Erdley, Newman, Mason, \& Carpenter, 2003), buffering against internalizing symptoms over time (Gaertner, Fite, \& Colder, 2010), safeguard from peer victimization (Crawford \& Manassis, 2011), and improvements of social skills (Glick \& Rose, 2011), besides having an overall positive influence on the psychological well-being of children (Parker \& Asher, 1993).

Various methodological approaches have been used in research to assess friendship quality in children (Schneider \& Greenman, 2003; Yugar \& Shapiro, 2001). Different studies have based their data collection on methods such as observation (e. g., Simpkins \& Parke, 2001; Weimer, Kerns, \& Oldenburg, 2004), storytelling (e. g., Smorti \& Pagnucci, 2003), drawing (e. g., Bombi, Cannoni, \& Pinto, 2003; Kosteniusa \& Öhrling, 2008), sociometric interview (e. g., Nadeau \& Tessier, 2009), among others. Some of these methods might be highly time-consuming and require extensive training - for example, to afford high-trained observers to collect adequate data. On the other hand, self-report measures are efficient, less expensive, can be administered to many children at the same time and are useful to investigate different domains of children friendships from the point of view of the respondents. Furthermore, specific characteristics of children friendships such as self-disclosure are best detected through self-report measures than observations, for example (Simpkins \& Parke, 2001). Despite all advantages listed, it is important to address that some constructs are difficult to evaluate through self-reports. Some traits and behaviors are difficult to a person to indentify in his or herself. Participants may present difficulties to recognize all personal behaviors, traits and beliefs.

Among self-report instruments developed to assess children friendship qualities, the Friendship Qualities Scale ([FQS]; Bukowski, Hoza, \& Borvin, 1994) and the Friendship Quality Questionnaire ([FQQ]; Parker \& Asher, 1993) are described in the literature as two frequently used measures (Kiesner et al., 2005). The FQQ was developed to assess children's perceptions of qualitative aspects of their very best friendship in six domains: intimate exchange; conflict resolution; companionship and recreation; help and guidance; validation and caring; and conflict and betrayal. The instrument demonstrated good validity (Parker \& Asher, 1993) and reliability (e. g., Kiesner et al., 2005; Parker \& Asher, 1993; Simpkins \& Parke, 2001; Simpkins, Parke, Flyr, \& Wild, 2006) evidences in previous studies. The FQQ has been used in various studies to investigate the friendship quality of children and its relations with different variables such as similarities between friend's perceptions of the same friendship (Simpkins et al., 2006); depression symptoms and feelings of loneliness (Nangle et al., 2003); parental discipline (Pike \& Eley, 2009); peer victimization (Crawford \& Manassis, 2011); among others.

It is valuable to examine the applicability and the psychometric properties of the FQQ in different cultures and countries. For example, anal- 
yses of the psychometric properties of an Italian version of the FQQ (Kiesner et al., 2005) demonstrated good reliability evidences, but yielded a notable difference in the original factor structure model proposed by Parker and Asher (1993): in the Italian study, one specific item from the "Conflict and Betrayal" factor ("can count on to keep promises", item 21, with negative loading in the original version of the FQQ) loaded more strongly in the "Validation and Caring" factor (positively) than in its original factor. In the original "Conflict and Betrayal" factor, the item 21 is the only item with a negative loading and also the only one representing the betrayal domain. Therefore, Kiesner et al. (2005) relocated this item to the "Validation and Caring" subscale, turning the "Conflict and Betrayal" factor into a "Conflict" factor only. However, the referred study used only these two FQQ subscales in their analyses, what does not represent a full-comparable model to the original scale. Still, the results of Kiesner et al. (2005) suggest that the item 21 of the FQQ might need further considerations in the final structure of the questionnaire.

The objective of the present study was to investigate psychometric properties of the Friendship Quality Questionnaire in a community sample of Brazilian children and early adolescents. Specifically, the aims of this study were: (1) to examine the factor structure of the FQQ in the Brazilian sample by means of Confirmatory Factor Analysis (CFA); (2) to investigate the internal consistency of the FQQ; and finally (3) to examine gender differences on friendship quality scores in the FQQ.

\section{Method}

\section{Participants}

Two hundred and eight-three (283) Brazilian children participated in the main study. These children were recruited from public schools in the cities of Porto Alegre - RS (44.4\%) and Florianópolis - SC (55.6\%). Nine participants (3.2\%) presented missing data in their answers for the FQQ items and were therefore excluded from the analyses.
The final sample consisted of 274 children aged 9-13 years $(M=10.46 ; S D=0.81)$, including $143(52.2 \%)$ males with a mean age of 10.43 (SD $=0.84)$ years old and $131(47.8 \%)$ females with a mean age of $10.50(S D=0.77)$ years old. The excluded group did not significantly differ from the researched group in terms of demographic characteristics.

\section{Instrument}

The Friendship Quality Questionnaire (FQQ) is an instrument developed to assess children's perceptions of qualitative aspects of their very best friendship (Parker \& Asher, 1993). The FQQ is a 40-item self-report measure, divided into six factors: "Intimate Exchange" (6 items, e. g., "tell each other secrets"); "Conflict Resolution" (3 items, e. g., "get over our arguments really quickly"); "Companionship and Recreation" (5 items, e. g., "always sit together at lunch"); "Help and Guidance" (9 items, e. g., "do special favors for each other"); "Validation and Caring" (10 items, e. g., "tells me I am good at things"); and "Conflict and Betrayal" (7 items, e. g., "argue a lot"). The instructions request the children to indicate how true a particular quality is of their relationship with their very best friend. After an initial warm-up item, the children score the 40 items of the questionnaire in a 5-point scale ranging from not at all true (0) to really true (4).

The study of Parker and Asher (1993) investigated psychometric properties of the original version of the FQQ. The instrument presented satisfactory structure coefficients of the items, ranging from 0.55 to 0.88 . The internal consistency measured by the Cronbach's alpha of the six factors was also satisfactory, ranging from 0.73 (Conflict Resolution) to 0.9 ("Help and Guidance"; "Validation and Caring"). The subscales corresponding to the six factors were moderately to highly intercorrelated, with Pearson's rs ranging from 0.16 to 0.75 . Only the "Conflict and Betrayal" factor correlated negatively with the other factors; all other subscales presented positive intercorrelations. 


\section{Procedures}

The FQQ was translated to Brazilian Portuguese by two independent translators. Both translations were synthesized into a single Brazilian Portuguese version that was then back-translated to English by another translator. All translators involved in this process were fluent in both languages. The synthesized forward translation and the back-translation were evaluated together with the original FQQ by a committee of experts composed by four Brazilian Ph.D. and a NorthAmerican Ph.D. all specialized in the field of peer relationships and child developmental psychology. The adjustment of the Brazilian version of the FQQ was performed after reaching a consensus among the members of the committee. After that, a pretest was conducted with a group of eleven children aged 9-11 years. Participants of this pilot study were requested to read and then rephrase the sentences in the questionnaire. The answers were analyzed to investigate possible problems on the wording of the Brazilian version of the FQQ and detect confusing or misleading items. No items were eliminated or significantly changed during the translation and pre-test processes. The Brazilian translation is available upon request to the first author.

Participants were asked to complete the Brazilian version of the FQQ in the schools. The FQQ was administered to all students that agreed to participate and whose parents gave informed consent regarding the research project. The questionnaire was answered by youth in the classrooms collectively. The instructions were read aloud by the researchers that supervised each administration of the questionnaire (child by child), stressing the importance of answering all items in the scale.

\section{Data Analysis}

Confirmatory Factor Analysis (CFA) was used to verify whether the six-factor model proposed by Parker and Asher (1993) fit to the Brazilian version of the FQQ. As the data did not justify the assumption of multivariate normality within the sample - the value of Mardia's normalized multivariate kurtosis was 29.18 -, estimation was conducted using the robust maximum likelihood (ML) estimation method with the Satorra-Bentler scaled chi square $\left(\mathrm{S}-\mathrm{B} \chi^{2}\right)$. Three hypothesized models were tested and compared: (1) the original six-factor model as proposed by Parker and Asher (1993); (2) a six-factor model similar to the original, but with the item 21 relocated from the "Conflict and Betrayal" factor to the "Validation and Caring" factor as proposed by Kiesner et al. (2005); and (3) a new six-factor model similar to the original, but with the exclusion of the item 21 from the scale, since it presented problems in the study of Kiesner et al. (2005) with the "Conflict and Betrayal" factor, but it does not theoretically relate to the "Validation and Caring" factor as conceptualized by Parker and Asher (1993).

Goodness-of-fit indexes used for evaluating the adequacy of the models were: Satorra-Bentler scaled chi square ([S-B $\left.\chi^{2}\right]$; Satorra \& Bentler, 2001); Comparative Fit Index (CFI); Tucker-Lewis Index (TLI); Root Mean Square Error of Approximation with 90\% Confidence Interval (RMSEA-90\% CI); Standardized Root Mean Square Residual (SRMR); and Average Standardized Residual (ASR). Criteria used to interpret the indexes were based on specialized literature (Byrne, 2010; Hu \& Bentler, 1999): values of the CFI and TLI above 0.9 or close to 0.95 represent a good fit; values of the RMSEA, SRMR, and ASR close to or below 0.05 represent a good fit, and below 0.08 represent an acceptable fit. Also, in order to evaluate the differences and improvements between models, the $\Delta \chi^{2}$ was used, with a significant $\Delta \chi 2$ indicating substantial improvement in model fit (Byrne, 2010).

The internal consistency of the FQQ total score and the subscale scores were assessed by calculating the Cronbach's alpha coefficients. Analyses of variance (ANOVA) and effect size statistics (Cohen's $d$ ) were used to investigate possible gender differences. The values for the scores of the groups in the ANOVA are reported as means and standard deviations. All $p$-values are based on two-tailed tests with alphas set at $5 \%$. 


\section{Results}

The first model tested (Model 1) was the original six-factor model proposed by Parker and Asher (1993) with all 40 items of the FQQ. As depicted in Table 1, Model 1 did not provide very good fit to the data, especially in terms of the CFI, TLI, and SRMR indexes. Factor loadings were all higher than 0.4 (ranging from 0.406 to 0.791 ) except for the item 21 ("can count on to keep promises"), which presented a factor loading of 0.171 .

As previously discussed, in the original structure FQQ, the item 21 is the only item with a negative coefficient included in the "Conflict and Betrayal" subscale and also the only one regarding the betrayal construct of this subscale (Parker \& Asher, 1993). The remaining six items in the factor relate to the conflict construct with positive loadings ("argue a lot"; "fight a lot"; "get mad a lot"; "doesn't listen to me"; "bug each other a lot"; and "sometimes says mean things about me to other kids"). Based on these theoretical assumptions and on the suggestion from the study of Kiesner et al. (2005), Model 2 was tested relocating the item 21 to the "Validation and Caring" subscale. The "Conflict and Betrayal" factor in Model 2 was thus renamed only "Conflict".

Model 2 had a significantly better fit than Model $1\left(\Delta \chi^{2}=121.9, p<0.001\right)$ and presented overall good fit indexes (CFI, TLI, RMSEA, SRMR, ASR) (Table 1). Factor loadings were all higher than 0.4 (ranging from 0.406 to 0.794). However, as previously discussed, the original structure of the FQQ did not theoretically consider the item 21 to be part of the "Validation and Caring" subscale. Therefore,
Model 3 was tested, maintaining the same six-factor structure from Model 2, but excluding the item 21 from the scale.

Model 3 had a slightly better fit than Model 2 $\left(\Delta \chi^{2}=65.39, p=0.003\right)$ and also presented slightly better indexes (CFI, TLI, RMSEA) (Table 1). Factor loadings were all higher than 0.4 (ranging from 0.406 to 0.792 ). As Model 3 had the best fit and avoided problems related to the discrepancies in the literature about the item 21 of the FQQ, psychometric properties of this model were further investigated.

Except for the "Conflict" subscale, the remaining five factors presented high positive intercorrelations $(0.67 \leq r s \leq 0.94)$ with $p<0.001$. The "Conflict" subscale did not significantly correlated $(p>0.1)$ to the other factors except for a very weak correlation with the "Validation and Caring" subscale $(r=0.15, p=0.021)$. Regarding the reliability of the FQQ, the Cronbach's alpha coefficients demonstrated satisfactory internal consistency of the total and the subscale scores. The alpha for the FQQ total score was 0.94. Concerning the subscales, alphas varied from 0.603 for "Conflict Resolution" to 0.901 for "Help and Guidance" (Table 2).

The total and subscale scores of the FQQ were compared between girls $(n=131)$ and boys $(n=$ 143). The scores were calculated by the sum of the item scores - the "Conflict" subscale items had their scores reversed so that higher total and subscale scores consistently indicated better quality friendships. Therefore, total scores range from 0 to 156 and subscale scores range from 0 to $i \mathrm{x} 4$, where $i$ is the number of items in each subscale (see Table 2).

TABLE 1

Goodness-of-fit Indexes in the CFA of the Models for the Friendship Quality Questionnaire

\begin{tabular}{cccccccc}
\hline Model & S-B $\chi^{2}(\mathrm{df})$ & $\mathrm{S}-\mathrm{B} \chi^{2} / \mathrm{df}$ & $\mathrm{CFI}$ & TLI & RMSEA [90\% CI] & SRMR & ASR \\
\hline M1 & $1222.62(725)$ & 1.686 & 0.891 & 0.883 & $0.05[0.045-0.055]$ & 0.098 & 0.061 \\
M2 & $1100.72(725)$ & 1.518 & 0.918 & 0.911 & $0.044[0.038-0.049]$ & 0.056 & 0.046 \\
M3 & $1035.33(687)$ & 1.507 & 0.921 & 0.915 & $0.043[0.038-0.048]$ & 0.056 & 0.046 \\
\hline
\end{tabular}

Note. S-B $\chi^{2}$ : Satorra-Bentler scaled chi square; CFI: comparative fit index; TLI: Tucker-Lewis Index; RMSEA: root mean square error of approximation; CI: confidence interval; SRMR: standardized root mean square residual; ASR: average standardized residual; M1: six-factor model identical to the original FQQ model; M2: six-factor model with the item 21 relocated to the "Validation and Caring" subscale; M3: six-factor model with the item 21 excluded from the scale.

Source: own work 
TABLE 2

Number of Items, Factor Loadings, and Internal Consistency Coefficients (Cronbach's Alphas) of the Friendship Quality Questionnaire and its Subscales

\begin{tabular}{cccc}
\hline Scale / Subscale & Number of items & Factor loadings range & Cronbach's $\alpha$ \\
\hline Friendship Quality Questionnaire & 39 & $0.406-0.792$ & 0.94 \\
Validation and Caring & 10 & $0.465-0.767$ & 0.874 \\
Help and Guidance & 9 & $0.644-0.748$ & 0.901 \\
Companionship and Recreation & 5 & $0.406-0.677$ & 0.685 \\
Intimate Exchange & 6 & $0.639-0.792$ & 0.848 \\
Conflict Resolution & 3 & $0.506-0.687$ & 0.603 \\
Conflict & 6 & $0.455-0.747$ & 0.777 \\
\hline
\end{tabular}

Source: own work

As depicted in Table 3, the FQQ total score was significantly different $(p=0.034)$ between boys and girls. Regarding the subscales, only the "Validation and Caring" subscale and the "Intimate Exchange" subscale scores were significantly different $(p=$ 0.004 and $p<0.001$, respectively) between genders. Females were found to score higher on the FQQ total score and on these two subscale scores. The gender differences showed small to moderate effect magnitudes, with Cohen's $d$ of 0.26 for the total score, 0.35 for the "Validation and Caring" subscale score and 0.46 for the "Intimate Exchange" subscale score.

\section{Discussion}

The present study investigated psychometric properties of the Friendship Quality Questionnaire (FQQ) in a community sample of Brazilian children and early adolescences. The FQQ demon- strated a six-factor structure as suggested in its original theoretical conceptualization (Parker \& Asher, 1993), but with better fit after the exclusion of the item 21, which had already presented problems in a previous study with an Italian version of the questionnaire (Kiesner et al., 2005). The "Conflict and Betrayal" subscale was thus renamed "Conflict" only for the Brazilian version. Furthermore, our data revealed all positive scales in the FQQ were highly intercorrelated with strong magnitude, whereas the "Conflict" subscale - the only negative subscale - did not correlate significantly or strongly with the others. This finding is consistent with theoretical assumptions of the literature that children who report a high level of one positive feature in their friendship usually report that their friendship is high in all other positive features, what supports the idea that positive features are all connected in a single dimension of friendship quality (Berndt, 2002). This strong correlation

TABLE 3

Comparison of the Friendship Quality Questionnaire Total and Subscale Scores between Gender Groups

\begin{tabular}{lccccc}
\hline & Boys M (SD) & Girls M (SD) & $F$ & $p$ & Cohen's $d$ [95\% CI] \\
\hline FQQ total score & $82.82(28.13)$ & $89.72(25.24)$ & 4.54 & 0.034 & $0.26[0.02-0.5]$ \\
Validation and Caring & $23.23(8.92)$ & $26.11(7.55)$ & 8.27 & 0.004 & $0.35[0.11-0.59]$ \\
Help and Guidance & $21.71(8.57)$ & $22.72(8.20)$ & 0.98 & 0.323 & $0.12[-0.12-0.36]$ \\
Companionship and Recreation & $11.17(4.32)$ & $11.57(4.35)$ & 0.58 & 0.449 & $0.09[-0.15-0.33]$ \\
Intimate Exchange & $11.9(6.3)$ & $14.66(5.76)$ & 14.19 & $<0.001$ & $0.46[0.22-0.7]$ \\
Conflict Resolution & $7.44(2.92)$ & $7.70(2.68)$ & 0.6 & 0.441 & $0.09[-0.14-0.33]$ \\
Conflict (reversed) & $7.36(5.44)$ & $6.95(5.18)$ & 0.39 & 0.532 & $0.08[-0.16-0.31]$ \\
\hline
\end{tabular}

Note. M: mean; SD: standard deviation; 95\% CI: confidence interval of 95\%.

Source: own work 
among positive features of friendships has led other researchers to use adapted or shortened versions of friendship quality self-report measures such as FQQ with only two factors: "positive qualities" and "conflict" (Biggs, Nelson, \& Sampilo, 2010; Weimer et al., 2004). Shortened versions of the FQQ also presented good reliability evidences in previous studies (e. g., Nangle et al., 2003; Pike \& Eley, 2009), what suggests that future work might benefit from the evaluation of the psychometric properties of a potential shortened Brazilian version of the FQQ.

The Brazilian version of the FQQ showed good reliability as measured by internal consistency. Our findings, in agreement with previous research, have demonstrated higher reliability alpha scores reported for the "Help and Guidance" and "Validation and Caring" subscales, and lower reliability alpha scores for the "Conflict Resolution "and "Companionship and Recreation" subscales (Parker \& Asher, 1993; Simpkins \& Parke, 2001; Simpkins et al., 2006).

Our data suggested that girls scored significantly higher in the FQQ, more specifically in the "Validation and Caring" and "Intimate Exchange" subscales when compared to boys. Considering the importance of analyzing the effect size (ES) in this type of comparison (García, Campos, \& Sánchez, 2011), our findings showed a small ES on the gender differences for the total score of the FQQ, but moderate ES on the gender differences for the two referred specific subscales. Research has consistently noted that females report significantly higher degree of positive friendship qualities than males (Weimer et al., 2004) and that these differences usually concern disclosure, intimacy, and companionship qualities (Simpkins et al., 2006). The study of Parker and Asher (1993) also showed similar gender differences in FQQ' "Validation and Caring" and "Intimate Exchange" subscale scores. Therefore, our findings regarding gender differences in reported friendship quality were consistent with the book of the literature. However, as Linden-Andersen, Markiewicz, and Doyle (2009) alert, it is still not clear whether these gender differences might be accounted for self-reporting biases or are due to actual higher levels of good friendship quality among girls' friendships.

The present study has some limitations. The major limitation is that all participants came from two specific urban South regions in Brazil. Therefore the extent to which our results apply to other Brazilian regions, as well as to non-urban children or children that are not attending schools is unknown. For instance, previous studies with Brazilian street children have found specific patterns of friendship among this population that are related to the developmental context of the street and might not be assessed by the items in the FQQ (e. g., Neiva-Silva, 2008). It is very important to replicate these results with other samples in different regions and contexts to extend the validity of the Brazilian version of the FQQ. Another limitation is that, once the main objective of this study was to investigate psychometric properties of the FQQ in Brazil, our results regarding friendship qualities were solely based on children's self-reports. Despite having its benefits as previously discussed, this type of measure also presents some limitations such as the fact that answers depend on the verbal and cognitive skills of the children (Simpkins \& Parke, 2001). Therefore a multi-method approach could be useful in providing a more complete assessment of the quality of children's friendships.

Findings of the present study overall demonstrate good evidences of validity and reliability of the FQQ, suggesting it can be a useful and reliable instrument to assess friendship quality in Brazilian children. The FQQ is a self-report measure easy to administer and score, inexpensive, and time-efficient. Given the importance of high-quality friendships for promoting benefits in children's development, the Brazilian version of the FQQ may be a valuable instrument for psychologists, pediatric clinicians, and all childhood researchers to evaluate interventions focused on social development of children. FQQ can be used in clinical psychological settings to discuss with youth about their social lives. FQQ can be also a value tool to improve psychosocial interventions in schools promoting children and adolescents' well-being and good-quality social relationships. 


\section{References}

Berndt, T. J. (2002). Friendship quality and social development. Current Directions in Psychological Science, 11(1), 7-10. http://dx.doi.org/10.1111/1467$\underline{8721.00157}$

Biggs, B. K., Nelson, J. M., \& Sampilo, M. L. (2010). Peer relations in the anxiety-depression link: Test of a mediation model. Anxiety, Stress $\mathcal{E}$ Coping: An International Journal, 23(4), 431-447. http://dx.doi. org $/ 10.1080 / 10615800903406543$

Bombi, A. S., Cannoni, E., \& Pinto, G. (2003). Le interviste silenziose: studiare le relazioni amicali attraverso il disegno. Età Evolutiva, 75, 97-103.

Bukowski, W. M., Hoza, B., \& Boivin, M. (1994). Measuring friendship quality during pre- and early adolescence: The development and psychometric properties of the Friendship Qualities Scale. Journal of Social and Personal Relationships, 11(3), 471484. http://dx.doi.org/10.1177/0265407594113011

Bukowski, W. M., Motzoi, C., \& Meyer, F. (2009). Friendship as process, function, and outcome. In K. H. Rubin, W. M. Bukowski \& B. Laursen (Eds.), Handbook of peer interactions, relationships, and groups (pp. 217-231). New York: The Guilford Press.

Byrne, B. M. (2010). Structural equation modeling with AMOS: Basic concepts, applications, and programming (2nd ed.). New York: Taylor and Francis Group.

Crawford, M., \& Manassis, K. (2011). Anxiety, social skills, friendship quality, and peer victimization: An integrated model. Journal of Anxiety Disorders, 25(7), 924-931. http://dx.doi.org/10.1016/j.janxdis.2011.05.005

Fordham, K., \& Stevenson-Hinde, J. (1999). Shyness, friendship quality, and adjustment during middle childhood. Journal of Child Psychology and Psychiatry, 40(5), 757-768. http://dx.doi.org/10.1111/1469. $\underline{7610.00491}$

Gaertner, A. E., Fite, P. J., \& Colder, C. R. (2010). Parenting and friendship quality as predictors of internalizing and externalizing symptoms in early adolescence. Journal of Child and Family Studies, 19(1), 101-108. http://dx.doi.org/10.1007/s10826009-9289-3
García, J. G., Campos, E. O., \& Sánchez, L. F. (2011). The use of the effect size in JCR Spanish Journals of Psychology: From theory to fact. The Spanish Journal of Psychology, 14(2), 1050-1055. http:// dx.doi.org/10.5209/rev_SJOP.2011.v14.n2.49

Glick, G. C., \& Rose, A. J. (2011). Prospective associations between friendship adjustment and social strategies: Friendship as a context for building social skills. Developmental Psychology, 47(4), 11171132. http://dx.doi.org/doi:10.1037/a0023277

Hu, L., \& Bentler, P. M. (1999). Cutoff criteria for fit indexes in covariance structure analysis: Conventional criteria versus new alternatives. Structural Equation Modeling, 6(1), 1-55. http://dx.doi. org/10.1080/10705519909540118

Kiesner, J., Nicotra, E., \& Notari, G. (2005). Target specificity of subjective relationship measures: $\mathrm{Un}$ derstanding the determination of item variance. Social Development, 14(1), 109-135. http://dx.doi. org/10.1111/j.1467-9507.2005.00293.x

Kosteniusa, C., \& Öhrling, K. (2008). 'Friendship is like an extra parachute': Reflections on the way schoolchildren share their lived experiences of well $\square$ being through drawings. Reflective Practice: International and Multidisciplinary Perspectives, 9(1), 23-35. http://dx.doi.org/10.1080/14623940701816634

Linden-Andersen, S., Markiewicz, D., \& Doyle, A. (2009). Perceived similarity among adolescent friends: The role of reciprocity, friendship quality, and gender. The Journal of Early Adolescence, 29(5), 617-637. http://dx.doi.org/10.1177/0272431608324372

Nadeau, L., \& Tessier, R. (2009). Social adjustment at school: Are children with cerebral palsy perceived more negatively by their peers than other at-risk children? Disability and Rehabilitation, 31(4), 302-308. http://dx.doi.org/10.1080/09638280801945899

Nangle, D. W., Erdley, C. A., Newman, J. E., Mason, C. A., \& Carpenter, E. M. (2003). Popularity, friendship quantity, and friendship quality: Interactive influences on children's loneliness and depression. Journal of Clinical Child and Adolescent Psychology, 32(4), 546-555.

Neiva-Silva, L. (2008). Uso de drogas entre crianças e adolescentes em situação de rua: Um estudo longitudinal. Doctoral Dissertation, Institute of Psychology, 


\section{Psychometric Properties of the Brazilian Version of the Friendship Quality \\ Questionnaire in a Community Sample of Children and Early Adolescents}

Universidade Federal do Rio Grande do Sul, Porto Alegre-RS, Brazil.

Parker, J. G., \& Asher, S. R. (1993). Friendship and friendship quality in middle childhood: Links with peer group acceptance and feelings of loneliness and social dissatisfaction. Developmental Psychology, 29(4), 611-621. http://dx.doi.org/10.1037/0012$\underline{1649.29 .4 .611}$

Pike, A., \& Eley, T. C. (2009). Links between parenting and extra-familial relationships: Nature or nurture? Journal of Adolescence, 32(3), 519-533. http:// dx.doi.org/10.1016/j.adolescence.2008.07.002

Satorra, A., \& Bentler, P. M. (2001). A scaled difference chi-square test statistic for moment structure analysis. Psychometrika, 66(4), 507-514. http://dx. doi.org/10.1007/BF02296192

Schneider, B. H., \& Greenman, P. S. (2003). Measuring children's friendships: The challenges in accessing a co-constructed state of mind. Età Evolutiva, 75, 70-78.

Simpkins, S. D., \& Parke, R. D. (2001). The relations between parental friendships and children's friend- ships: Self-report and observational analysis. Child Development, 72(2), 569-582. http://dx.doi. org/10.1111/1467-8624.00297

Simpkins, S. D., Parke, R. D., Flyr, M. L., \& Wild, M. N. (2006). Similarities in children's and early adolescents' perceptions of friendship qualities across development, gender, and friendship qualities. The Journal of Early Adolescence, 26(4), 491-508. http:// dx.doi.org/10.1177/0272431606291941

Smorti, A., \& Pagnucci, S. (2003). Le parole dell'amicizia: studiare le relazioni amicali attraverso le storie. Età Evolutiva, 75, 88-96.

Weimer, B. L., Kerns, K. A., \& Oldenburg, C. M. (2004). Adolescents' interactions with a best friend: Associations with attachment style. Journal of Experimental Child Psychology, 88(1), 102-120. http:// dx.doi.org/10.1016/j.jecp.2004.01.003

Yugar, J. M., \& Shapiro, E. S. (2001). Elementary children's school friendship: A comparison of peer assessment methodologies. School Psychology Review, 30(4), 568-585. 
